\title{
Two approaches to derive a proposal for added sugars intake for German children and adolescents
}

\author{
Ute Alexy*, Mathilde Kersting and Verena Schultze-Pawlitschko \\ Research Institute of Child Nutrition Dortmund (FKE), Heinstueck 11, D-44225 Dortmund, Germany
}

Submitted 2 December 2002: Accepted 1 April 2003

\begin{abstract}
Objective: Intake of sugars is restricted in most international food guides. However, in recent recommendations quantified limits of added sugars intake have not been given, although deemed necessary by those who criticised the recommendations. Design: Two approaches to derive a scientifically based quantified limit of added sugars intake for German children and adolescents are suggested. For the first dietary survey approach, 5120 three-day weighed dietary records from the Dortmund Nutritional and Anthropometric Longitudinally Designed (DONALD) Study were used. Added sugars intakes in records of high vs. low dietary quality, measured by a nutrient intake score, were compared. For the second approach, a total dietary concept for German children and adolescents developed and evaluated by the Research Institute of Child Nutrition - the Optimised Mixed Diet - was used

Results: Whereas in the latter dietary concept an added sugars intake of about $6 \%$ of energy intake is tolerated, the dietary survey approach resulted in only small differences between high and low dietary quality, with a median added sugars intake of $12 \%$ of energy in records with high dietary quality.

Conclusions: A reasonable dietary quality is possible within higher ranges of added sugars intake than derived from the dietary concept approach. Therefore we suggest a range of intake of added sugars for German children and adolescents, from 6\% to 12\% of energy.
\end{abstract}

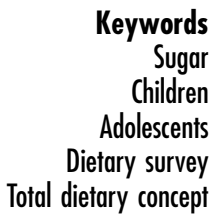

Intake of sugars is restricted in most international food guides. However, in recent recommendations, no quantitative limit of sugars intake has been given. For example, the Food and Agriculture Organization/World Health Organization Joint Expert Consultation stated that 'Excessive intakes of sugars which compromise micronutrient density should be avoided' ${ }^{1}$. In the most recent Dietary Guidelines for Americans it is advised: 'Choose beverages and foods to moderate your intake of sugars' ${ }^{2}$. One of the guidelines for a balanced diet, published by the British Health Education Authority, says: 'Don't have sugary foods and drinks too often' ${ }^{3}$ and the German Nutrition Society says: 'Foods and beverages containing sugar and sugar substitutes should be consumed only occasionally'4 .

However, several authors postulate a need for a quantified limit of added sugars intake ${ }^{5,6}$, reasoning firstly that consumers need essential precise information as to what is meant by 'moderate intake', 'not too often' or 'occasionally' and secondly that dietary guidelines, e.g. the American Food Guide Pyramid, as a nutrition education tool, claims a 'total diet' approach, which requires quantities of all energy sources in the $\operatorname{diet}^{5}$. Since added sugars intake in children and adolescents is in general higher than in other population groups ${ }^{1,5,7}$, a precise limit is of particular interest for these age groups.

The main reason for a limited or moderate added sugars intake is its nutrient dilution effect ${ }^{1}$; i.e. added sugars provide energy but no essential nutrients, so that nutrient density decreases ${ }^{7-11}$. The first food guides published by the US Department of Agriculture already stated that sugar 'spoils the child's appetite for ... other important things ${ }^{, 12}$.

Two approaches for deriving a proposal for a quantitative limit of added sugars intake are conceivable: (1) the analysis of dietary survey data and (2) the total diet concept. In this paper we use both these approaches to look at the present-day diet of children and adolescents in Germany.

\section{Subjects and methods}

\section{Dietary survey}

For the first approach, we used dietary records to compare the added sugars intake of children and adolescents achieving high dietary quality with the added sugars 
intake of those showing low dietary quality; quality being measured by a nutrient intake score. For this purpose, data from the Dortmund Nutritional and Anthropometric Longitudinally Designed (DONALD) Study, an ongoing mixed longitudinal cohort study started in 1985, were used. In the DONALD Study, detailed data on diet, metabolism, growth and development from healthy subjects between infancy and adulthood (once a year for subjects older than 2 years) are collected. Details have been described elsewhere ${ }^{13,14}$. The nutrition survey comprises a weighed dietary record on three consecutive days. Energy and nutrient intakes were calculated using our nutrient database LEBTAB, which is updated continuously with all newly recorded food items including fortification.

\section{Definition of added sugars}

Added sugars were defined as all refined sugars (e.g. sucrose, maltose, lactose, glucose, dextrin) eaten separately at the table or used as ingredients in processed or prepared foods, as done in the recent scientific literature ${ }^{2,10,15-17}$. Although natural intrinsic sugars and added sugars are indistinguishable with regard to chemical analysis or physiological metabolism, this separation provides consumers with useful information ${ }^{15,18}$.

\section{Dietary quality index}

To estimate dietary quality, we calculated an overall Dietary Quality Index (DQI) based on nutrient intakes. Table 1 shows 12 selected goals for an adequate diet, including nutrients of preventive interest (fat, cholesterol, fibre and water) and those vitamins and minerals for which the mean intake does not reach the reference intake in the DONALD Study ${ }^{19}$. Sums of the individual scores gave a range for the DQI between 0 and 12. The DQI was stratified into low and high, using the median (DQI = 5) as cut-off point.

\section{Statistical analysis}

The Statistical Analysis System ${ }^{\circledR}$ version 8.00 (SAS Institute, Cary, NC, USA) was used for data analysis. We used the SAS Macro GLIMMIX, a generalised mixed linear model, in which the means of the data and the covariance structure, and the effect of repeated measurements, were measured $^{20}$. An exponential structure of covariance was

Table 1 Nutritional goals* for calculating the Dietary Quality Index

Fat intake $\leq 35 \%$ of energy

Saturated fatty acids $\leq 10 \%$ of energy

Dietary cholesterol $<100 \mathrm{mg} / 1000 \mathrm{kcal}$

Dietary fibre $>10 \mathrm{~g} / 1000 \mathrm{kcal}$

Water intake $>1 \mathrm{~g} / \mathrm{kcal}$

Vitamins (A, E, C, B , folate) $\dagger$

Minerals (calcium, iron)†

\footnotetext{
${ }^{*}$ Deutsche Gesellschaft für Ernährung, $2000^{4}$.

$\dagger>75 \%$ of reference, assuming that reference value is defined as nutrient requirement plus one standard deviation $(\approx 25 \%)$.
}

specified to consider correlation of repeated measurements dependent on the absolute time interval of repeated measurements within the same subject.

Normally, energy intake is positively associated with nutrient intake. Therefore, this variable was also included in our model, as well as time (years since the beginning of the DONALD Study) and age (in years).

\section{The Optimised Mixed Diet}

For the second approach, we used a total diet concept for German children and adolescents, the Optimised Mixed Diet (OMD). Total diet concepts give food-based recommendations reflecting national dietary habits to achieve energy and all nutrient needs, and are aimed at the prevention of chronic nutrition-related diseases. First published in $1993^{21,22}$, the OMD is continuously adapted to new scientific knowledge. The basis of the OMD is a proposal for daily amounts of the 12 food groups comprising the total diet. These food group amounts were derived from 7-day sample menus given by 4-6year-old children and 13-14-year-old boys and girls, which had been checked for nutrient adequacy ${ }^{23}$. Considering energy reference values, food group amounts for younger and older age groups can then be estimated by interpolation. Since sample menus reflect everyday dietary habits, practical criteria (e.g. known food preferences of children and adolescents, traditional German meal habits, common easily available foods, and kitchen food preparation) could be considered.

\section{Results}

\section{Dietary survey approach}

Between 1986 and 2001, a total of 5120 dietary records from 842 children and adolescents (417 males, 425 females) aged 2-18 years, coming from 617 families, were collected and are evaluated here.

Table 2 shows sample characteristics, and overall intakes of energy and added sugars. To validate dietary recording, the ratio of reported energy intake (EI) to predicted basal metabolic rate (BMR) was used as proposed by Goldberg et al. ${ }^{24}$. EI/BMR ratios were in the recommended range of plausible dietary information according to Torun et $a$. $^{25}$.

As shown in Table 3, distribution of DQI was skewed, with more records with a low DQI. Between 13\% (4-18year-old boys) and 21\% (4-18-year-old girls) had very low DQI $(<3)$. Only 3\% had very high DQI $(>8)$. No record reached the maximal DQI of 12 . Only $2 \%$ of the records reached the goal for saturated fatty acids, approximately $5-8 \%$ for folate, $20-30 \%$ for cholesterol, fibre and water, $30-40 \%$ for vitamin $\mathrm{E}$ and fat, $40-50 \%$ for vitamin $\mathrm{A}$ and $>50 \%$ for vitamins $\mathrm{C}$ and $\mathrm{E}$, calcium and iron.

Table 4 shows overall intakes of energy and added sugars stratified by records with high and low DQI. Energy intake (\% of reference) was lower, but intake of added 
Table 2 Sample characteristics, overall energy intake and added sugars intake (mean \pm standard deviation) in 2-18-year-old participants of the Dortmund Nutritional and Anthropometric Longitudinally Designed Study, 1986-2001

\begin{tabular}{lccc}
\hline & Boys and girls, 2-3 years & Boys, 4-18 years & Girls, 4-18 years \\
\hline Number of records & 1018 & 2046 & 2056 \\
Age (years) & $2.80 \pm 0.64$ & $9.32 \pm 3.79$ & $9.16 \pm 3.74$ \\
Energy intake (MJ day ${ }^{-1}$ ) & $4.50 \pm 0.87$ & $7.68 \pm 2.20$ & $6.52 \pm 1.60$ \\
Energy intake/basal metabolic rate & $1.36 \pm 0.23$ & $1.46 \pm 0.27$ & $1.40 \pm 0.27$ \\
\hline
\end{tabular}

sugars (\% of energy) was higher in records with low DQI than in records with high DQI. A significantly positive age effect was found in 4-18-year-old girls, and a significantly positive time effect was found in 2-3-year-olds (data not shown).

Regarding those $3 \%$ of records with very high DQI ( $>8)$, nutritional goals for saturated fatty acids (82\%), folic acid (51\%), cholesterol (39\%) and water (32\%) were not reached most frequently (data not shown).

Figure 1 shows intake distribution of added sugars (\% of energy) stratified by records with low and high DQI. Differences were small in total, but greatest in 2-3-yearold children. Here, approximately $41 \%$ of records with low DQI but $53 \%$ of records with high DQI had added sugars intakes below $10 \%$ of energy. In 4-18-year-old boys these values were $22 \%$ vs. $28 \%$, respectively, and in 4-18-yearold girls $24 \%$ vs. $34 \%$, respectively. Overall, the median of added sugars intake in records with low and high DQI was $12.5 \%$ of energy and $11.5 \%$ of energy, respectively. In some records with high DQI, added sugars intakes over $20 \%$ of energy were found.

\section{Total diet approach}

Table 5 gives age-dependent food group amounts of the OMD for 4-6-year-old children and 13-14-year-old boys and girls. With the OMD, new Reference Values of Nutrient Intake $^{4}$ except folate ( $72 \%$ of reference value) are reached, including the recommendations for the prevention of chronic nutrition-related diseases corresponding to the left column in Table 1 (fat: 31\% of energy, saturated fatty acids: $10 \%$ of energy, cholesterol: $71 \mathrm{mg} / 1000 \mathrm{kcal}$, dietary fibre: $16 \mathrm{~g} / 1000 \mathrm{kcal}$, water: $1.3 \mathrm{~g} / 1000 \mathrm{kcal})$.

In the OMD, a differentiation is made between recommended food groups having high nutrient densities and tolerated foods with low nutrient densities. Recommended food groups amount to approximately $90 \%$ of total energy intakes and almost $100 \%$ of intakes of vitamins

Table 3 Distribution of Dietary Quality Index (DQI) (\% of records) in 2-18-year-old participants of the Dortmund Nutritional and Anthropometric Longitudinally Designed Study, 1986-2001

\begin{tabular}{lccc}
\hline DQI & $\begin{array}{c}\text { Boys and girls, } \\
\text { 2-3 years }\end{array}$ & $\begin{array}{c}\text { Boys, } \\
\text { 4-18 years }\end{array}$ & $\begin{array}{c}\text { Girls, } \\
\text { 4-18 years }\end{array}$ \\
\hline $0-2$ & 15.9 & 12.6 & 21.4 \\
$3-5$ & 49.8 & 48.3 & 49.7 \\
$6-8$ & 30.8 & 35.8 & 26.3 \\
$9-11$ & 3.4 & 3.3 & 2.7 \\
\hline
\end{tabular}

and minerals. Therefore, sweetened foods liked by most children and adolescents, e.g. sweets, cakes, chocolate and sweetened beverages, can be tolerated in moderate amounts without compromising the nutrient adequacy of the diet. Added sugars make up to $6 \%$ of total energy intake, which means approximately half of the energy portion of total tolerated foods.

\section{Discussion}

No single figure for a proposal of added sugars intake could be deduced from the two approaches presented here.

\section{The dietary survey approach}

Differences between added sugars intakes of children and adolescents from the DONALD Study with a high and low DQI were only small. This was confirmed by the distributions of added sugars intakes, which were nearly congruent in 4-18-year-old children and adolescents, regardless of the level of DQI.

Obviously, high dietary quality is possible within a wide range of sugars intake. However, recent research work showed a general trend of declining nutrient density ${ }^{10,26}$ or declining nutrient intake $\mathrm{e}^{9,11,27}$ with increasing percentage of energy from sugars. Therefore added sugars intake should not be fully liberalised.

Also, in previous publications, no exact limit for added sugars intake could be derived from dietary data. Linseisen et $\mathrm{al}^{7}{ }^{7}$, who examined the influence of total sucrose on nutrient intakes in German children and adults, suggested upholding the former limit of $10 \%$ of energy. Gibson? found no compromised nutrient intakes up to about 20\% of energy in British pre-school children and 17\% of energy from sugars in British adults ${ }^{8}$. However, Gibson used nonmilk extrinsic sugars (NMES); i.e. all sugars originating from the cell walls of plants, without lactose in milk ${ }^{1}$. Comparing the effects of added sugars, NMES and total sugars $^{8}$, added from sugars account for approximately $85 \%$ of NMES. Thus, $16 \%$ of energy and $20 \%$ of energy from NMES correspond to $14 \%$ of energy and $17 \%$ of energy from added sugars. Furthermore, Linseisen et $a l^{7}$ and Gibson $^{8,9}$ only considered the effects of sugars on vitamins and minerals. In our analysis, further nutrients important for preventive aspects, such as fat, saturated fatty acids and cholesterol intake, were also regarded. Not surprisingly, it 
Table 4 Overall intakes (mean \pm standard deviation) of energy and added sugars in 2-18-year-old participants of the Dortmund Nutritional and Anthropometric Longitudinally Designed Study (1986-2001), stratified by records with high and low Dietary Quality Index (DQI)

\begin{tabular}{|c|c|c|c|c|c|c|c|c|c|}
\hline & \multicolumn{3}{|c|}{ Boys and girls, $2-3$ years } & \multicolumn{3}{|c|}{ Boys, $4-18$ years } & \multicolumn{3}{|c|}{ Girls, $4-18$ years } \\
\hline & $\begin{array}{c}\text { Low DQI } \\
(2.9 \pm 1.1)\end{array}$ & $\begin{array}{c}\text { High DQI } \\
(6.3 \pm 1.3)\end{array}$ & $P$-value & $\begin{array}{c}\text { Low DQI } \\
(3.0 \pm 1.1)\end{array}$ & $\begin{array}{c}\text { High DQI } \\
(6.3 \pm 1.2)\end{array}$ & $P$-value & $\begin{array}{c}\text { Low DQI } \\
(2.7 \pm 1.2)\end{array}$ & $\begin{array}{l}\text { High DQI } \\
(6.2 \pm 1.2)\end{array}$ & $P$-value \\
\hline $\begin{array}{l}\text { MJ (\% of reference) } \\
\text { Added sugars } \% \text { of eneray) }\end{array}$ & $\begin{array}{l}93.7 \pm 15.5 \\
11.1 \pm 5.1\end{array}$ & $\begin{array}{c}103.9 \pm 19.8 \\
9.9 \pm 5.0\end{array}$ & 0.0001 & $\begin{array}{l}84.2 \pm 16.3 \\
13.4+50\end{array}$ & $\begin{array}{l}95.1 \pm 18.0 \\
128+52\end{array}$ & 0.0449 & $\begin{array}{l}83.4 \pm 17.3 \\
13.3+5.2\end{array}$ & $\begin{array}{l}94.2 \pm 17.5 \\
121+5.3\end{array}$ & 0.0001 \\
\hline
\end{tabular}

was just these nutritional goals that were not reached in records with very high DQI $(>8)$, since lower added sugars intake often leads to a high fat intake ${ }^{7-9,17}$.

The American Institute of Medicine ${ }^{15}$ stated in their recent Dietary Reference Intakes for carbohydrates that there is insufficient evidence to set a Tolerable Upper Limit (UL) for added sugars or total (sum of added and naturally occurring) sugars. A maximal intake level of $25 \%$ or less of energy from added sugars is suggested based on the decreased intake of some micronutrients of American sub-populations exceeding this level. However, regarding median nutrient intakes by range of added sugars intake published therein, reduced intakes of some nutrients were observed even below $25 \%$ of energy from added sugars ${ }^{15}$.
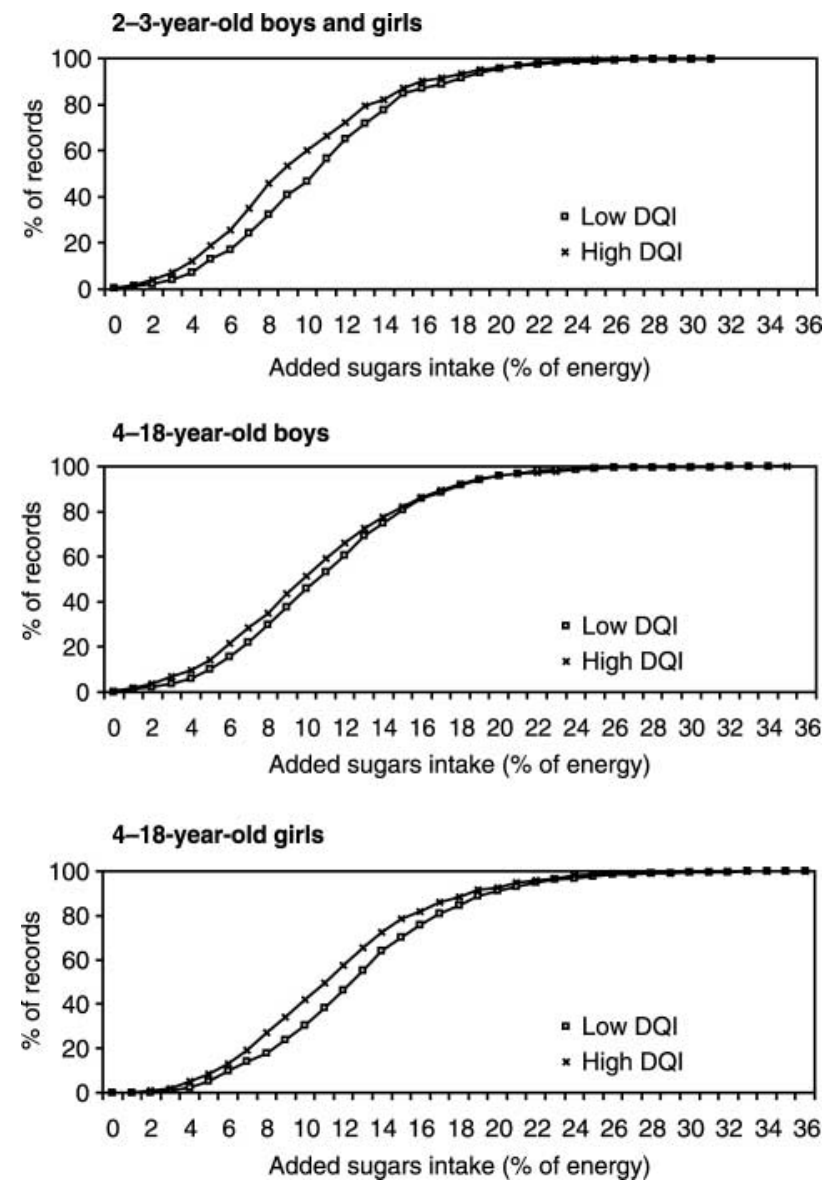

Fig. 1 Cumulative distribution of added sugars intake for records with low and high Dietary Quality Index (DQI) in children and adolescents from the Dortmund Nutritional and Anthropometric Longitudinally Designed Study
In the DONALD Study, nutrient dilution in children and adolescents also started at lower added sugars levels ${ }^{26,28}$.

Total dietary indexes give the opportunity to judge several indicators of dietary quality simultaneously. Using a comparable approach, Löwik et al. ${ }^{29}$ found no differences in intake of the sum of mono- and disaccharides in middle-aged women with a low, moderate and high food-based quality score (20.8\%, $20.0 \%$ and $21.0 \%$ of energy, respectively), whereas energy intake increased by $27.6 \%$. Likewise in the DONALD Study energy intake increased with increasing DQI, supporting the positive influence of energy intake on overall nutrient intake. However, even in those records with high DQI ( $>$ median), only half of our selected dietary goals $(n=6)$ were reached simultaneously on average.

\section{The total dietary concept approach}

With the second approach, the overall dietary concept OMD, the total of nutritional goals, i.e. micro- and

Table 5 Proposals for age- and sex-dependent average daily food amounts and concomitant energy intakes (references) by 4-6-year-old children and 13-14-year-old boys and girls

\begin{tabular}{|c|c|c|c|}
\hline & \multicolumn{3}{|c|}{ Age (years) } \\
\hline & \multirow[b]{2}{*}{$4-6$} & \multicolumn{2}{|c|}{$13-14$} \\
\hline & & Boys & Girls \\
\hline Energy intake $\left(\mathrm{kcal} \mathrm{day}^{-1}\right)$ & 1450 & 2700 & 2200 \\
\hline \multicolumn{4}{|c|}{$\begin{array}{l}\text { Recommended food groups with high nutrient density } \\
\quad(\geq 80 \% \text { of total energy intake) }\end{array}$} \\
\hline \multicolumn{4}{|c|}{ Liberal } \\
\hline Beverages (ml day ${ }^{-1}$ ) & 800 & 1300 & 1200 \\
\hline Grains $\left(\mathrm{g}\right.$ day $\left.^{-1}\right)$ & 170 & 300 & 250 \\
\hline Potatoes $^{*}\left(\mathrm{~g}\right.$ day $\left.^{-1}\right)$ & 130 & 250 & 200 \\
\hline Vegetables $\left(\mathrm{g}_{\text {day }}{ }^{-1}\right)$ & 200 & 300 & 260 \\
\hline Fruits $\left(\right.$ g day $\left.^{-1}\right)$ & 200 & 300 & 260 \\
\hline \multicolumn{4}{|l|}{ Moderate } \\
\hline Dairy, cheese (ml (g) day ${ }^{-1}$ ) & 350 & 450 & 425 \\
\hline Meat, sausage $\left(\mathrm{g} \mathrm{day}^{-1}\right)$ & 40 & 75 & 65 \\
\hline Eggs (pieces week ${ }^{-1}$ ) & 2 & $2-3$ & $2-3$ \\
\hline Fish $\left(\mathrm{g}\right.$ week $\left.^{-1}\right)$ & 100 & 200 & 200 \\
\hline \multicolumn{4}{|l|}{ Sparing } \\
\hline Oil, margarine, butter $\left(\mathrm{g} \mathrm{day}^{-1}\right)$ & 25 & 40 & 35 \\
\hline \multicolumn{4}{|c|}{$\begin{array}{l}\text { Tolerated food groups with low nutrient density } \\
\text { ( } \leq 10 \% \text { of total energy intake) }\end{array}$} \\
\hline Sugary foods $†\left(g\right.$ day $\left.^{-1}\right)$ & 10 & 20 & 15 \\
\hline Sugary and fatty foods $\ddagger\left(\mathrm{g} \mathrm{day}^{-1}\right)$ & 40 & 75 & 60 \\
\hline
\end{tabular}

* Or pasta, rice, cereals.

†E.g. sweets, honey, sugar, or amounts of soft drinks 10 times as high. $\ddagger$ E.g. chocolate, cake. 
macronutrient intakes, were considered. Here, added sugars intake amounts to $6 \%$ of energy, which is below the limits derived from dietary surveys.

A quantitative limit of added sugars intake was also discussed in the context of the common world-wide overall dietary concept, the Dietary Guidelines for Americans, visualised as the Food Guide Pyramid ${ }^{5,18}$. Using the number of servings of each of the food groups that are suggested to meet nutrient adequacy goals for three energy levels and restricting choices of foods to their lowest fat forms with no added sugars, amounts of free energy that might be spent as added sugars ranged between $6 \%$ of energy for a total of $1600 \mathrm{kcal}(6.7 \mathrm{MJ}), 8.7 \%$ of energy for $2200 \mathrm{kcal}(9.2 \mathrm{MJ})$ and $10.3 \%$ of energy at $2800 \mathrm{kcal}(11.7 \mathrm{MJ})$. Such an energy-dependent limit of added sugars intake seems reasonable in adults, since energy intake is the major predictor of nutrient intake $\mathrm{e}^{11,28}$ but nutrient requirements are almost constant. However, in children and adolescents, energy needs increase with age, as do most nutrient requirements. Therefore, for these age subgroups, an almost constant nutrient density is appropriate as is considered in the OMD.

International expert groups have demanded that foodbased dietary guidelines should be developed which take into account the customary dietary habits and ecological, socio-economic and cultural setting in which the population lives ${ }^{30}$. This means that food-based dietary guidelines have to be specific for a specific country. The OMD is an overall dietary concept developed specifically for German children and adolescents. However, foodbased dietary guidelines from different industrialised Western countries agree in principle, e.g. in favouring high intakes of foods from plant origin. Also, the lowest level of added sugars from the US overall dietary concept and 6\% of energy derived from the German OMD are well below or reach the former limit of $10 \%$ of energy from added sugars.

The present-day added sugars intake in the DONALD Study, even in children and adolescents with high dietary quality, exceeded all these limits. One reason for such differences between total diet concepts and real practices can be found in food fortification. In the present-day diet of children and adolescents, fortified food, e.g. beverages, dairy or cereals, contribute considerably to the intake of vitamins and minerals in Germany ${ }^{31}$ and the $\mathrm{USA}^{32}$ for example, but often these foods also contain added sugars. Therefore foods that are simultaneously fortified with vitamins and minerals and sweetened with added sugars mask nutrient dilution ${ }^{26}$.

Added sugars may dilute not only nutrients, but also non-nutrient food components. Forshee and Storey ${ }^{16}$ showed that individuals who consume more added sugars are predicted to eat more grains but fewer vegetables and fruits. Such foods not only provide vitamins and minerals, but also phytochemicals. Therefore, a balanced diet with common foods and a high percentage of foods from plant origin, as suggested in the OMD and the Food Guide Pyramid, has advantages that cannot be replaced by simple food fortification. Also the US Institute of Medicine $^{33}$ and the German Society for Nutrition ${ }^{4}$ propose normal nutrient-dense foods as first choice to reach nutrient recommendations. Although differences between food group intakes were small for different intake levels of added sugars ${ }^{16}$, the risk of a decrease in consumption particularly of fruits and vegetables should be minimised.

Krebs-Smith ${ }^{5}$ pointed out that only a small amount of food is able to reach the upper limit of added sugars intake calculated from the Food Guide Pyramid. Even for persons with a high individual energy requirement (for example $2800 \mathrm{kcal} \mathrm{day}^{-1}$ ), it is already reached by one large nondiet soft drink per day. In the OMD, between $25 \mathrm{~g}$ and $85 \mathrm{~g}$ sugary foods are allowed, depending on age (Table 5). However, the question arises of whether a diet with such a low added sugars content should be named 'poor in sugar' or 'poor in palatability' per se, since naturally occurring sugars also have a sweetening effect and support palatability.

\section{Conclusions}

In summary, the advantage of the total dietary concept or Optimised Mixed Diet is the achievement of all nutritional goals (macro- and micronutrients) solely by consuming common foods. The dietary survey concept considers present-day dietary practice, including fortification, but does not allow the same individual to reach all nutritional goals.

The limit of $6 \%$ of energy from added sugars in the OMD is an ambitious aim, which requires a clear reduction of present-day added sugars intake. However, a reasonable dietary quality is possible within a higher range of added sugars intake. Therefore, from a practical point of view, we suggest a range of added sugars intake for German children and adolescents, from 6\% of energy (added sugars intake with the OMD equal to the dietary concept approach) to $12 \%$ of energy (median of added sugars intake in records with high dietary quality).

Furthermore, total energy intake has a stronger association with dietary quality than does added sugars ${ }^{9,11}$. This stresses the importance of educating children not only on a healthy diet but also on increased physical activity, because an increased energy intake would lead to an increased nutrient intake.

\section{Acknowledgements}

This work was supported by the Ministry of Education, Science and Research North Rhine-Wesphalia, Germany and the German Federal Ministry of Consumer Protection, Food and Agriculture. The authors gratefully acknowledge the participants in the DONALD Study, Christa Chahda and Ruth Schäfer for collecting and 
coding the dietary records in the DONALD Study, and Diane Pavlitzek for proof reading.

\section{References}

1 Food and Agriculture Organization (FAO)/World Health Organization (WHO). Carbohydrates in Human Nutrition. Report of a Joint FAO/WHO Expert Consultation, Rome, 14-18 April 1997. FAO Food and Nutrition Paper 66. Rome: FAO, 1998.

2 US Department of Agriculture (USDA)/Department of Health and Human Services (DHHS). Nutrition and Your Health: Dietary Guidelines for Americans, 5 th ed. Home and Garden Bulletin No. 232. Washington, DC: USDA/DHHS, 2000.

3 Health Education Authority (HEA). Eight Guidelines for a Healthy Diet: A Guide for Nutrition Educators. Abingdon: HEA (in association with the Ministry of Agriculture, Fisheries and Food and the Department of Health), 1997.

4 Deutsche Gesellschaft für Ernährung. Referenzwerte für die Nährstoffzufubr [Reference Values for Nutrient Intakes]. Frankfurt: Umschau/Braus, 2000.

5 Krebs-Smith SM. Choose beverages and foods to moderate your intake of sugars: measurement requires quantification. Journal of Nutrition 2001; 131: 527S-35S.

6 Keenan DP, Abusabha R. The fifth edition of the Dietary Guidelines for Americans: lessons learned along the way. Journal of the American Dietetic Association 2001; 101: 631-4.

7 Linseisen J, Gedrich K, Karg G, Wolfram G. Sucrose intake in Germany. Zeitschrift für Ernabrungswissenschaft 1998; 37: 303-14.

8 Gibson SA. Do diets high in sugars compromise micronutrient intakes? Journal of Human Nutrition and Dietetics 1997; 10: 125-33.

9 Gibson SA. Non-milk extrinsic sugars in the diets of pre-school children: association with intakes of micronutrients, energy, fat and NSP. British Journal of Nutrition 1997; 78: 367-78

10 Lyhne N, Ovesen L. Added sugars and nutrient density in the diet of Danish children. Scandinavian Journal of Nutrition 1999; 43: 4-7.

11 Rugg-Gunn AJ, Hackett AF, Jenkins GN, Appleton DR. Empty calories? Nutrient intake in relation to sugar intake in English adolescents. Journal of Human Nutrition and Dietetics 1991; 4: 101-11.

12 Hunt CL. Food for young children. US Department of Agriculture, Farmers' Bulletin 1916; 717: 1-21.

13 Kersting M, Sichert-Hellert W, Lausen B, Alexy U, Manz F, Schöch G. Energy intake of 1 to 18 year old German children and adolescents. Zeitschrift für Ernabrungswissenschaft 1998; 37: 47-55.

14 Alexy U, Sichert-Hellert W, Kersting M. Fifteen-year time trends in energy and macronutrient intake in German children and adolescents: results of the DONALD study. British Journal of Nutrition 2002; 87: 595-604.

15 Institute of Medicine, Food and Nutrition Board, eds. Dietary Reference Intakes for Energy, Carbohydrate, Fiber, Fat, Fatty Acids, Cholesterol, Protein and Amino Acids. Washington, DC: National Academy Press, 2002.

16 Forshee RA, Storey ML. The role of added sugars in the diet quality of children and adolescents. Journal of the American College of Nutrition 2001; 20: 32-43.

17 Lewis CJ, Park YK, Dexter PB, Yetley EA. Nutrient intakes and body weights of persons consuming high and moderate levels of added sugars. Journal of the American Dietetic Association 1992; 92: 708-13.
18 Johnson RK, Frary C. Choose beverages and foods to moderate your intake of sugars: the 2000 Dietary Guidelines for Americans - what's all the fuss about? Journal of Nutrition 2001; 131: 2766S-71S.

19 Sichert-Hellert W, Kersting M, Manz F. Changes in timetrends of nutrient intake from fortified and non-fortified food in German children and adolescents - 15 year results of the DONALD study. European Journal of Nutrition 2001; 40: 49-55.

20 Littell RC, Milliken GA, Stroup WW, Wolfinger RD. SAS $S^{\circledR}$ System for Mixed Models. Cary, NC: SAS Institute, Inc., 1996.

21 Kersting M, Chahda C, Schöch G. Optimierte Mischkost als Präventionsernährung für Kinder und Jugendliche. Teil 1: Lebensmittelauswahl [Optimised Mixed Diet: a preventive diet for children and adolescents. Part 1: Food intake]. Ernährungs-Umschau 1993; 40: 164-9.

22 Kersting M, Zempléni S, Schöch G. Optimierte Mischkost als Präventionsernährung für Kinder und Jugendliche. Teil 2: Nährstoffzufuhr [Optimised Mixed Diet: a preventive diet for children and adolescents. Part 2: Nutrient intake]. Ernährungs-Umschau 1993; 40: 204-9.

23 Zempléni S, Kersting M, Schöch G. Optimierte Mischkost als Präventionsernährung für Kinder und Jugendliche. Teil 3: Speisepläne [Optimised Mixed Diet: a preventive diet for children and adolescents. Part 3: Sample menus]. Ernäbrungs-Umschau 1993; 40: B17-9.

24 Goldberg GR, Black AE, Jebb SA, Cole TJ, Murgatroyd PR, Coward WA, et al. Critical evaluation of energy intake data using fundamental principles of energy physiology: 1. Derivation of cut-off limits to identify under-recording. European Journal of Clinical Nutrition 1991; 45: 569-81.

25 Torun B, Davies PS, Livingstone MB, Paolisso M, Sackett R, Spurr GB. Energy requirements and dietary energy recommendations for children and adolescents 1 to 18 years old. European Journal of Clinical Nutrition 1996; 50(Suppl. 1): S37-80.

26 Alexy U, Sichert-Hellert W, Kersting M. Fortification masks nutrient dilution due to added sugars in the diet of children and adolescents. Journal of Nutrition 2002; 132: 2785-91.

27 Bowman SA. Diets of individuals based on energy intakes from added sugars. Family Economics and Nutrition Review 1999; 12: 31-8.

28 Alexy U, Sichert-Hellert W, Kersting M. Associations between added sugars intake and nutrient and food group intake in the diet of children and adolescents. British Journal of Nutrition 2003, in press.

29 Löwik MR, Hulshof KF, Brussaard JH. Food-based dietary guidelines: some assumptions tested for The Netherlands. British Journal of Nutrition 1999; 81(Suppl. 2): S143-9.

30 Food and Agriculture Organization (FAO)/World Health Oraganization (WHO). Preparation and Use of Food-based Dietary Guidelines. Report of a Joint FAO/WHO Consultation. WHO Technical Report Series No. 880. Geneva: WHO, 1999.

31 Sichert-Hellert W, Kersting M, Alexy U, Manz F. Ten-year trends in vitamin and mineral intake from fortified food in German children and adolescents. European Journal of Clinical Nutrition 2000; 54: 81-6.

32 Berner LA, Clydesdale FM, Douglass JS. Fortification contributed greatly to vitamin and mineral intakes in the United States, 1989-1991. Journal of Nutrition 2001; 131: 2177-83.

33 Institute of Medicine, Food and Nutrition Board, eds. Dietary Reference Intakes for Calcium, Phosphorus, Magnesium, Vitamin D, and Fluoride. Washington, DC: National Academy Press, 1999. 